\title{
The Awareness and Perception About The Ethical Concerns Related to The Biobanks Among Medical and Dental Practitioners: A Questionnaire Based Study
}

\author{
Mohammadi Begum Khan ${ }^{1 *}$, Faizan Ahmed Khan', Veena Vaswani², Uma Kulkarni ${ }^{\text {and Parvathy Ram Mohan }}{ }^{1}$ \\ 'Department Of Orthodontics, Yenepoya University, Deralakatte, Mangalore, India \\ ${ }^{2}$ Dept. Of Forensic Medicine, Yenepoya University, Deralkatte, Mangalore, India \\ ${ }^{3}$ Department Of Ophthalmology, Yenepoya University, Manglaore, India
}

\begin{abstract}
Background: The term "Biobank" has been used in different ways but one way is to define it as "an organized collection of human biological material and associated information stored for one or more research purposes". By definition, "Biobank" is a long-term storage and conservation facility for biological specimens, to support future scientific investigation. The aim of this study is to assess the awareness and perception of Biobanks, their existence, aims and objectives and the ethical concerns related to them, among the clinicians pertaining to both medical and dental specialties.
\end{abstract}

Methods: A questionnaire comprising of 31 questions of which few are purely awareness and rest are perception based is framed. The questions which were framed for the questionnaire, have few of them given direct responses as YES, NO, DON'T KNOW and the remaining of them have been graded into LIKERT'S SCALE, ranging from 1 to 5. Statistical analysis: After obtaining the response, the answers were plotted in MS-Excel sheet and analysed statistically for the Percentages, Frequencies, Chi-square and degree of Association ( $>0.05=$ No Association) between the two fraternities responses by using SPSS 22.0 version software. The p value was set at 0.05

Result: There was found a level of association between both the groups for certain sensitive questions relating to privacy of information and ownership claims.

Conclusion: It can be concluded that the willingness to participate in sample donation, motivation for sample donation are in agreement with each other, which is worth being further investigated.

Keywords: Biobanks, Awareness, Ethical Issues, Informed Consent, Clinical Practitioners

\section{Introduction}

The term "Biobank" has been used in different ways but one way is to define it as "an organized collection of human biological material and associated information stored for one or more research purposes". Collections of plant, animal, microbe, and other nonhuman materials may also be described as Biobanks but in some discussions the term is reserved for human specimens only. ${ }^{1}$ By definition, "Biobank" is a long-term storage and conservation facility for biological specimens, to support future scientific investigation. $^{2}$

Biobanks consist of two different parts: 1) The biologic material that is collected, processed, and long-time stored. 2) The database, including information about demographic and clinical data for each sample. Thus the scientific research has escalated its performance since the inception of these Biobanks which are heavily supported by government as the research results are highly beneficial to the society. In recent years there has been a great ramification in the practices and policymaking of these Biobanks as there is been an increasing diversity in the set of research purposes and types as well as source of research samples. ${ }^{3}$ For instance, Biobanks could comprise the collections of human bodily substances of all kinds, such as cells, tissues, blood, or DNA. They range in capacity from small collections of samples to large-scale national repositories. The collected samples could be populationbased or disease-specific, originating from diverse profile of individuals, eg, minors or adult persons. Biobanks are considered to be the storehouse of many biological samples which might range from being just anonymous to belonging to specific personal information. Also, the Biobanks might operate for various purposes such as diagnostic, therapeutic, or research. ${ }^{4}$

Key Organizations Associated with Biobanks: Some examples of organizations which participated in creating written guidelines about biobanking are the following: ${ }^{5}$

- World Medical Association, Council for International 
- Organizations of Medical Sciences,

- Council of Europe,

- Human Genome Organisation,

- World Health Organization, and UNESCO.

History of Biobank Governance: In 1998 the Icelandic Parliament passed the act on Health Sector Database which allowed for the creation of a national Biobank in that country. In 1999 the United States National Bioethics Advisory Commission issued a report containing policy recommendations about handling human biological specimens. ${ }^{6}$ In 2005 the United States National Cancer Institute founded the Office of Biorepositories and biospecimen Research so that it could have a division to establish a common database and standard operating procedures for its partner organizations with biospecimen collections. In 2006 the Council of the European Union adopted a policy on human biological specimens which was novel for discussing issues unique to Biobanks. ${ }^{6}$

The aim of this study is to assess the awareness and perception of Biobanks, their existence, aims and objectives and the ethical concerns related to them, among the clinicians pertaining to both medical and dental specialties.

\section{Objectives of the study}

$\checkmark$ To assess the level of awareness among the clinicians of both medical and dental field about the existence and goals of Biobanks

$\checkmark$ To assess their perception variations about the different issues related to Biobanks like their areas of interests, aims and objectives

$\checkmark$ To assess their perception variations about the ethical issues which are being faced by these Biobanks and the ownership claims chaos involved with them.

\section{Materials and Methods:}

A questionnaire comprising of 31 questions of which few are purely awareness and rest are perception based is framed and analyzed by the subject experts and also approved by the Ethical society of YENEPOYA UNIVERSITY. The questions which were framed for the questionnaire, have few of them given direct responses as YES, NO, DON'T KNOW and the remaining of them have been graded into LIKERT'S SCALE, wherein a range of 1 to 5 numbers have been given which have the interpretation as :

\section{Strongly agree (1), Agree (2), Don't know (3), Disagree} (4), and Strongly disagree (5).

The sample size was decided to be 50 for each medical and dental specialties comprising to a total of 100 sample size which was decided to be appropriate to judge the level of awareness and variations in perceptions. The questionnaire was distributed among the registered medical and dental practitioners preferably practicing in and around the Mangalore city located in the southern part of Karnataka, India, After obtaining the informed consent.

Statistical Analysis: After obtaining the response, the answers were plotted in MS-Excel sheet and analysed statistically for the Percentages, Frequencies, Chi-square and degree of Association ( $p>0.05=$ No Association) between the two fraternities responses by using SPSS 22.0 version software. The $\mathbf{p}$ value was set at $\mathbf{0 . 0 5}$. (QUESTIONNAIRE IS ATTACHED)

The sensitivity of the awareness and perception was assessed by taking Four questions from the questionnaire pertaining to awareness

$\checkmark$ About the type of volunteers to be encrolled in the Biobanks,

$\checkmark \quad$ Information sharing by the Biobanks( confidentiality issues),

$\checkmark$ Ownership claims faced by them

$\checkmark$ Their willingness to participate and the type of sample donation they prefer.

(The level of Association among the responses was assessed using Chi-square test.)

[The Selected Questions Were: Q.no.1: Do you think, a Biobank for its efficient progress and better scientific research results should look to recruit the following types of volunteers. Please rate them according to your perception. Q.no.2: Do you think the information about your donated tissue samples research results by the Biobank should be shared? If yes, with whom? Kindly show your degree of consent for the following choices given. Q.no.3: Please rate the following, for the Ownership claim (Intellectual property) about the research results of the specimen that you have donated to a Biobank. Q.no.4: If you are interested to donate your specimen which one do you prefer?]

\section{Result}

Results Obtained Using The Sensitive Questions Pertaining to Knowledge and Perception: The discussion about their perception level shows that both the groups have equally consented in majority for Likert scale 2 (agree) for types of participants (Volunteers) to be recruited for the Biobank to work efficiently for its genuine research results. When asked about the sharing of information about their research data, most of them in both the groups have consented in majority to be limited it to only themselves and there was strong disagreement to be shared with 
family members and relatives as well as disagreement was shown for publishing the data by both the groups. There was also found a level of ASSOCIATION between both the groups when their perception was assessed about the sharing of the research data with the researcher and the same Biobank. When the Ownership issues were assessed, both the groups have consented for sharing of the data with the donor only in majority followed by donor and Biobank

Table 1: Response chart for Q.no: 15.

\begin{tabular}{l|l} 
Q. NO.15 & Medical practitioners (Response in
\end{tabular} Likerts scale)

\begin{tabular}{|c|c|}
\hline$(1)$ & $2(38 \%)$ \\
\hline$(2)$ & $2(38 \%)$ \\
\hline$(3)$ & $2(38 \%)$ \\
\hline$(4)$ & $2(38 \%)$ \\
\hline
\end{tabular}

\begin{tabular}{|c|c}
$\begin{array}{c}\text { Dental practitioners } \\
\text { (Response in Likerts scale) }\end{array}$ & $2(50 \%)$ \\
\hline $1(36 \%)$ \\
\hline $1(42 \%)$ \\
\hline $2(36 \%)$
\end{tabular}

Level of Association

Table 2: Response chart for Q.no: 22.

\begin{tabular}{|c|c|c|c|}
\hline Q. NO.22 & $\begin{array}{c}\text { Medical practitioners } \\
\text { (Response in Likerts scale) }\end{array}$ & $\begin{array}{c}\text { Dental practitioners } \\
\text { (Response in Likerts scale) }\end{array}$ & Level of Association \\
\hline$(1)$ & $1(56 \%)$ & $1(72 \%)$ & No \\
\hline$(2)$ & $2(40 \%)$ & $2(34 \%)$ & No \\
\hline$(3)$ & $5(36 \%)$ & $5(38 \%)$ & Yes \\
\hline$(4)$ & $2(40 \%)$ & $1(38 \%)$ & No \\
\hline$(5)$ & $5(40 \%)$ & $5(40 \%)$ & Yes \\
\hline$(6)$ & $5(40 \%)$ & $5(36 \%)$ & Yes \\
\hline$(7)$ & $5(30 \%)$ & $2(26 \%)$ & No \\
\hline$(8)$ & $5(32 \%)$ & $2(26 \%)$ & No \\
\hline$(9)$ & $5(48 \%)$ & $5(34 \%)$ & No \\
\hline$(10)$ & $5(54 \%)$ & $5(48 \%)$ & \\
\hline
\end{tabular}

Table 3: Response chart for Q.no: 25.

\begin{tabular}{|c|c|c|c|}
\hline Q. NO.25 & $\begin{array}{c}\text { Medical practitioners } \\
\text { (Response in Likerts scale) }\end{array}$ & $\begin{array}{c}\text { Dental practitioners } \\
\text { (Response in Likerts scale) }\end{array}$ & \begin{tabular}{c} 
Level of Association \\
\hline$(1)$
\end{tabular}$\quad 1(38 \%)$ \\
\hline$(2)$ & $2 \& 3(30 \%)$ & $1(40 \%)$ & No \\
\hline$(3)$ & $3(34 \%)$ & $3(32 \%)$ & No \\
\hline$(4)$ & $2 \& 3(32 \%)$ & $5(32 \%)$ & No \\
\hline$(5)$ & $2(34 \%)$ & $1 \& 3(26 \%)$ & No \\
\hline$(6)$ & $2 \& 3(34 \%)$ & $2(30 \%)$ & No \\
\hline
\end{tabular}

Table 4: Response chart for Q.no: 29.

\begin{tabular}{|c|c|c|c|}
\hline Q. NO.29 & $\begin{array}{c}\text { Medical practitioners } \\
\text { (Response in Likerts scale) }\end{array}$ & $\begin{array}{c}\text { Dental practitioners } \\
\text { (Response in Likerts scale) }\end{array}$ & \begin{tabular}{c} 
Level of Association \\
\hline$(1)$
\end{tabular}$\quad 1(50 \%)$ \\
\hline$(2)$ & $5(28 \%)$ & $1(40 \%)$ & No \\
\hline$(3)$ & $5 \& 3(28 \%)$ & $5(40 \%)$ & No \\
\hline$(4)$ & $59(32 \%)$ & $5(38 \%)$ & No \\
\hline$(5)$ & $5(36 \%)$ & $5(44 \%)$ & No \\
\hline$(6)$ & $5(34 \%)$ & $5(42 \%)$ & No \\
\hline$(7)$ & $5(36 \%)$ & $5(42 \%)$ & No \\
\hline$(8)$ & $5(42.9 \%)$ & $5(44 \%)$ & $5(42 \%)$ \\
\hline
\end{tabular}

was the perception for medical practitioners but it was donor and researcher by the dental practitioners. When their willingness to participate and donate different parts was assessed, most of the dental practitioners have agreed for blood only and disagreed for all the organs donation, whereas most of medical practitioners have agreed for blood only and strongly disagreed for ova/ sperm followed by all the organs donation. 


\section{Discussion}

Our results illustrated a general public agreement to participate in Biobanking and emphasize the need to establish awareness campaigns to promote public involvement in biomedical research, which correlate with increased level of participation in biobanking. ${ }^{7}$ Speaking about the consent issues in Biobanking, Hoeyer K. $2012^{8}$ has reported that Biobanks usually collect sample and data for multiple future research and it is not feasible to obtain specific consent for any single research. It has been discussed that one-off consent or a broad consent for various research purposes may not suffice ethical and legal requirements.

Speaking about the children and incompetent adults participation in biobanking, Hens K et al. in $2009^{9}$ stated that the majority of Biobanks do not involve children because of special ethical problems and concerns that are not easily addressable, and also because the increased sensitivity of the public and the media toward this segment of the population sometimes makes it an unnecessary risk that many Biobanks are not willing to take. However, this could lead medical research on children to lag behind the research on adults. From the ethical point of view, in that way children will eventually suffer relatively more than adults. So, nearly all authors support the idea of involving children in Biobanks, but they also agree that the risk for them should be actively minimized.

When perception was assessed about the sharing of research data, the level of perception was found to be in accordance to what has been reported in other cultures where a high level of concern about protection of privacy was measured. i.e, limiting to oneself and not disclosing to others. ${ }^{10-14}$ These findings were in agreement with the study done by Kaufman DJ 2009 and Hansson MG in $2011^{15,16}$ which stated that the fundamental concern about privacy is usually also the main concern of the participants when they are deciding whether to donate their samples to Biobanks. Their study showed that up to $90 \%$ of people were concerned about their privacy Thus, concluded that consequences of breaking privacy could substantially affect public's willingness to participate and substantially delay the research. Therefore, Biobanks must always guarantee a maximal level of protection of participants. Another study by Cambon-Thomsen A. in $2011{ }^{17}$ reported about the privacy and identifiability of the samples and stated that there is a widespread concern that insurance companies and employers could access personal information. They usually have great interest in personal information and Biobanks must guarantee adequate protection of personal data. Further, results of research can also harm not only individuals, but the whole groups could feel stigmatized because of their genetic predisposition or other relevant information. Biobanks that perform research on a specific ethnic or other group of people must consider this and be very careful when publishing the results.

The level of awareness about the Biobanks and its working protocols as well as the ethical concerns were found to be closely matching between these groups. It was also found that the willingness to participate and organ donation was also nearly the same. Speaking about the public awareness about the Biobanks, Rothstein MA 2005 in ${ }^{18}$ focused about the commercialization aspect in Biobanking and stated that although Biobanks have a primary focus on research and improving medical knowledge, this will not necessarily prevent private companies from trying to use Biobank data for their own interest. In general, commertialization raises several ethical issues, such as preventing exploitation, ensuring fairness to study participants, and balancing costs and benefits. Some articles showed that commercialization, in general, tended to decrease public trust in Biobanks, although it did not completely diminish it.

However the Owner- ship claiming was found to be differing in the groups where dental practitioners have agreed it to shared it between donor and researcher whereas medical practitioners have agreed to be shared among donor and the Biobanks. This finding in general is found to be ambiguous as Chalmers D. in $2011^{19}$ has discussed about the ownership claims issues in the Biobanking sector and presented the ethical and legal issues that are encountered in this regard in the Biobanking. What happens when a participant donates a part of body to a Biobank? Could Biobanks become owners of the sample or does it remain in the ownership of the participants? Chalmers, has recently explored this issue in great depth and concluded that the legal position on ownership remained unsettled. Other authors take the position that complete anonymization would practically make biological materials ownerless, but that in all other instances the donors maintain ownership and should be able to withdraw both their consent and their biological material donated to the Biobank. Another study by Nwabueze, Remigius Nnamdi in $2007^{20}$ reported about an important aspect of Biobanking wherein the debate is about the ownership of the samples. As of 2007, Iceland had three different laws on ownership of the physical samples and the information they contain. Icelandic law holds that the Icelandic government has custodial rights of the physical samples themselves while the donors retain ownership rights. In contrast, Tonga and Estonia give ownership of Biobank samples to the government, but their laws include strong protections of donor rights. Our study however, revealed that the percentage is maximum for ownership claiming between the donor and the researcher. This suggests that the researcher has the value of trust more 
than the Biobank for the noble purpose of research among the educated public groups.

\section{Conclusion}

This questionnaire based survey has given information about comprehension and motivation of both medical and dental practitioners towards Biobanking and its aims, objectives, research obligations as well as the ethical issues about consent, sharing of research information, willingness to participate in sample donation, motivation for sample donation and ownership claims, which is worth being further investigated. As the level of understanding of aims and methods of a specific research project seems to vary in relation to modalities of approaching research, most of the participants are seemingly motivated by a "pragmatic"or a "selfless attitude" to contribute to research.

This study also suggests that people may have a "responsibility or an obligation" to participate in research are not new, especially where risks are considered low for participants; even if the "dilemma or quandary" between respect of autonomy and respect of solidarity cannot be completely overcoming, a balance can still be continuously pursued.

\section{Acknowledgements}

All The Authors And Yenepoya University

\section{Reference}

1. Greely, H. T. "The Uneasy Ethical and Legal Underpinnings of Large-Scale Genomic Biobanks". Annual Review of Genomics and Human Genetics. 2007; 8: 343-364.

2. Artene S A, Ciurea ME, Purcaru S O, Tache DE. Biobanking in a Constantly Developing Medical World ; The ScientificWorld Journal 2013.

3. Hewitt, R. E. "Biobanking: The foundation of personalized medicine". Current Opinion in Oncology. 2011; 23 (1): 112-119.

4. Fullerton, S. M.; Anderson, N. R.; Guzauskas, G.; Freeman, D.; Fryer-Edwards, K. "Meeting the Governance Challenges of Next-Generation Biorepository Research". Science Translational Medicine. 2010; 2: (15)

5. Cambon-Thomsen, A.; Rial-Sebbag, E.; Knoppers, B. M. "Trends in ethical and legal frameworks for the use of human biobanks". European Respiratory Journal. 2007; 30 (2): 373-382.
6. Haga, S.; Beskow, L. "Ethical, Legal, and Social Implications of Biobanks for Genetics Research". Genetic Dissection of Complex Traits. Advances in Genetics. 2008; 60: 505-544

7. Gaskell G, Gottweis H, Starkbaum J et al: Publics and biobanks: Pan-European diversity and the challenge of responsible innovation. Eur J Hum Genet 2013; 21: 14-20.

8. Hoeyer K. Trading in Cold Blood? Trust in Biobanking 2012; 21-41.

9. Hens K, Nys H, Cassiman JJ, Dierickx K. Genetic research on stored tissue samples from minors: a systematic review of the ethical literature. Am J Med Genet A. 2009;149A: 2346-58.

10. Tupasela A, Sihvo S, Snell K, Jallinoja P, Aro AR, Hemminki E: Attitudes towards biomedical use of tissue sample collections, consent, and biobanks among Finns. Scand J Public Health 2010; 38: 46-5

11. Beskow LM, Dean E: Informed consent for biorepositories: assessing prospective participants' understanding and opinions. Cancer Epidemiol Biomarkers Prev 2008; 17: 1440-1451.

12. Ahmad M, Al Gamal E, Othman A, Nasrallah E: Knowledge, attitudes and practices towards cancer prevention and care in Jordan. Report 2011.

13. Asai A, Ohnishi M, Nishigaki E, Sekimoto M, Fukuhara S, Fukui T: Attitudes of the Japanese public and doctors towards use of archived information and samples without informed consent: preliminary findings based on focus group interviews. BMC Med Ethics 2002; 3: 21-27.

14. Willison DJ, Keshavjee K, Nair K, Goldsmith C, Holbrook AM: Computerization of Medical Practices for the Enhancement of Therapeutic Effectiveness investigators. Patients' consent preferences for research uses of information in electronic medical records: interview and survey data. BMJ 2003; 326: 31 .

15. Hansson MG. The need to downregulate: A minimal ethical framework for Biobank research. Methods Mol Biol. 2011;675:39-59.

16. Kaufman DJ, Murphy-Bollinger J, Scott J, Hudson KL. Public opinion about the importance of privacy in Biobank research. Am J Hum Genet. 2009;85:643-54.

17. Cambon-Thomsen A. The social and ethical issues of postgenomic human Biobanks. Nat Rev Genet.2004;5:866-73

18. Rothstein MA. Expanding the ethical analysis of Biobanks. J Law Med Ethics. 2005;33:89-101.

19. Chalmers D. Genetic research and Biobanks. Methods Mol Biol. 2011; 675:1-37.

20. Nwabueze, Remigius Nnamdi . Biotechnology and the Challenge of Property: Property Rights in Dead Bodies. Aldershot, England: Ashgate Press 2007; 169- 170.

*Corresponding author:

Dr. Mohammadi Begum Khan, Fellow (Cleft Orthodontics), Department Of Orthodontics, Yenepoya University, Deralakatte, India 575018. Phone: +917338502550

Email: sabiakareem127@gmail.com

Date of Submission : 09.03.2017 